\title{
$O$ aprender como fator de mudança nas organizações
}

\author{
Alex Moreira ${ }^{1}$ \\ alexmoreira@terra.com.br
}

\section{Resumo}

O estudo aqui apresentado parte de uma nova perspectiva. Buscar-se mostrar um pouco das subjetividades nas relações humanas no trabalho, mais precisamente como o aprender pode gerar modificações nas práticas sociais no trabalho. A articulação teórica foi forjada a partir de conceitos fundados em Phillipe Zarifian, Pierre Bourdieu e Anthony Giddens. O estudo a partir do qual se originou foi desenvolvido em uma organização de porte industrial, situada no município de Contagem, Minas Gerais, líder em seu segmento no ramo de eletrônicos/ informática. Os dados foram obtidos a partir de entrevistas feitas com trabalhadores responsáveis por diversas funções e em vários setores da organização, além de exaustiva imersão em campo. Sua utilização nas análises viabilizou a construção teórica propriamente dita e articulação dos autores, possibilitando concluir que a aprendizagem pode ser importante fator catalisador dos processos de reflexibilidade nas organizações, em consequência de mudança nas mesmas.

Palavras-chave: Aprendizagem; qualificação; habitus; reflexibilidade.

\footnotetext{
${ }^{1}$ Doutor em Ciências Sociais pela Pontifícia Universidade Católica de São Paulo (PUC/SP); mestre em Administração Pública pela Fundação João Pinheiro; especialista em Educação pelo Centro de Estudos e Pesquisas Educacionais de Minas Gerais da Universidade do Estado de Minas Gerais (CEPEMG/UEMG) e licenciado em Geografia pela PUC de Minas Gerais. Atualmente atua como Árbitro da Câmara Mineira de Mediação e Arbitragem (Caminas) e como coordenador da Câmara Setorial de Relações de Ensino. É professor do Programa de Mestrado da FEAD, professor adjunto da PUC/MG e UEMG. Atua com ênfase em aprendizagem escola/organizações, gestão de pessoas, trabalho e negociação.
}

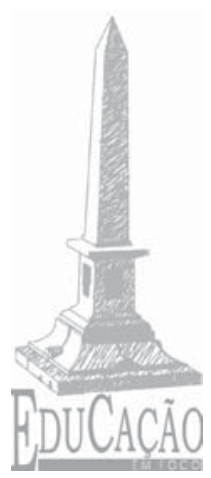

83 


\section{Introdução}

$\mathrm{Na}$ análise acadêmica de situações de trabalho, tem sido comum o predomínio de uma perspectiva objetivista talvez como consequência natural de uma maior utilização de correntes teóricas, como o contingencialismo e o institucionalismo, que percebem a organização fundamentalmente como reflexo das características do ambiente no qual se insere. Dessa forma, as interações sociais, entre elas tanto os processos de aprendizagem quanto o comportamento das pessoas no ambiente de trabalho, são entendidas apenas como estratégias na busca da sobrevivência organizacional no mercado. A partir dessa visão, os processos sociais e culturais que dão forma à estrutura e ao comportamento organizacional têm sido entendidos como aspectos externos ao processo estruturador dos fenômenos estudados, isto é, como fatores que influenciariam os objetos estudados de fora para dentro e não como componentes do problema.

Ao revés dessa tendência, neste artigo, busca-se mostrar um pouco dessas subjetividades nas relações humanas no trabalho, mais precisamente como o aprender pode gerar modificações nas práticas sociais no trabalho.

Essa temática aparece com mais relevância ao recordar-se Giddens (1990). Segundo o autor, a forma tradicional da organização social que surge na Europa a partir do século XVIII perde o lugar privilegiado que teve em épocas pré-modernas em favor daquilo que ele nomeia como "reflexividade institucional". Institucional por fazer parte da atividade social atual e reflexiva porque os discursos (e práticas sociais) transformam a realidade na qual o próprio discurso é formado, o que possibilita ao sujeito definir-se e redefinir-se quanto a seu cotidiano.

Como consequência, Giddens entende que esta reflexividade traz complicações para a autoidentidade do sujeito na medida em que ele próprio se autoconstrói como se fosse um projeto, embora entenda também que tal reflexividade pressupõe alguma autono- 
mia de ação, apontando para o que considera uma forma de democratização da vida privada e pública. Parece lícito pressupor, como resultado, que essa reflexividade também ocorre no trabalho, o que se pretende observar de forma subsidiária a partir do estudo dos fenômenos que compõem a definição ou transformação dos sujeitos sociais no trabalho assalariado.

Já as teorias de Bourdieu contribuem para este estudo por constituírem-se bases teóricas para o desafio do entendimento dos processos de resignificação das camadas de sentido que foram "assimiladas" pela prática social, ou seja, constituíram-se naquilo que o autor chama "habitus".

"Habitus" é um conceito bastante antigo, que remonta à era medieval e foi recuperado nos anos de 1960 por Bourdieu (1992) em sua construção de uma teoria disposicional ${ }^{2}$ da ação. Seu objetivo foi reintroduzir a análise da capacidade inventiva ou não dos indivíduos (ou agentes, como Bourdieu prefere) nos estudos antropológicos que desenvolvia, sem com isso retroceder a outras abordagens que, em sua opinião, poderiam enviesar o entendimento da conduta social.

A teoria disposicional que Bourdieu propõe, aqui entendida como pertinente à questão, tem como ponto central esse duplo processo de interiorização através da relação de influência recíproca entre as estruturas objetivas (dos campos sociais - variáveis técnicas e estruturais da organização) e as estruturas incorporadas (do "habitus" atitudinais). De acordo com o autor, as pessoas e o mundo social ${ }^{3}$ se movem em uma relação "simbiótica" onde, na análise das práticas ou comportamentos sociais, deve ser levado em conta o que foi incorporado pelos indivíduos a partir do que são guiados por um conjunto de comportamentos (habitus) adquiridos da estrutura objetiva e

\footnotetext{
${ }^{2}$ Nela o princípio das ações não é a consciência, a intenção, o projeto, a intenção racional como nas teorias do individualismo metodológico ou da rational action theory, mas das disposições, quer dizer das maneiras de ser permanentes que podem estar na origem das ações dotadas de todos os sinais de finalidade sem que os fins atingidos tenham sido colocados enquanto tal por uma ação da consciência (SOIHET, 2008).

${ }^{3}$ A noção de sociedade presente na obra de Pierre Bourdieu é substituída pela noção de "mundo social" e a de estrutura social pela ideia de "campo". Assim o mundo social é composto de estruturas, indivíduos, grupos, habitus etc.
}

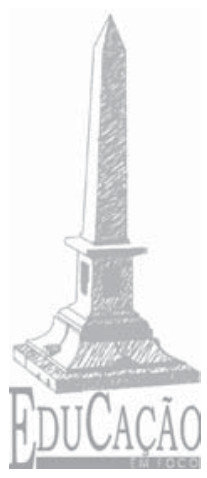

85 
assimilados como princípios de visão e de divisão do mundo social. Assim, em sua visão, o mundo social é desenvolvido a partir de estruturas cognitivas constituídas historicamente.

Não se pode esquecer, no entanto, que as relações entre as pessoas e instituições são dinâmicas, o que, em princípio, pressupõem a possibilidade da mudança das relações de trabalho no tempo. Tal caráter importa fundamentalmente em resignificações do que tenha sido aprendido ou até mesmo na intensidade com que se aprende, consequentemente, podendo levar a mudanças posturais, processuais, nas práticas sociais, no trabalho assalariado ou, em última instância, institucionais.

Dessa forma, cabe questionar a efetividade dos processos de qualificação profissional enquanto catalisadores de mudanças nas práticas sociais no trabalho da indústria moderna e pretendidos por seus empregadores, visando à melhoria da competitividade.

Entendendo que importante parte da construção da identidade do trabalhador moderno enquanto trabalhador assalariado advém da construção social do conhecimento no trabalhar, torna-se importante o estudo dos processos de aprendizado nas organizações e seu papel na ruptura de obstáculos para o rompimento com antigos saberes e aquisição de novos, e mesmo, saber se a construção de novos saberes se consubstancia em novas práticas profissionais. O grande obstáculo à criação desses saberes é a cristalização de valores e formas de agir. Esse é o objeto deste artigo.

Quanto à unidade de estudo ou campo de pesquisa, foi escolhida uma organização industrial de médio porte que conta atualmente com um portfólio de 40 projetos em no-breaks e vários de softwares ligados a seu funcionamento e gerenciamento, além do controle de mais de $70 \%$ do mercado em seu segmento de atuação.

A pesquisa realizada se constitui em um estudo qualitativo, exploratório e que se ateve fundamentalmente ao ambiente de manufatura ou setores de alguma forma a eles ligados, ou seja, transformadores e bobinas, montagem, laboratório, projeto e suporte, com mais de 120 horas de observação em campo e 14 entrevistas. 
Enquanto referência, os entrevistados foram nomeados de forma aleatória como entrevistado 1 , entrevistado 2 e assim por diante.

\section{Qualificação, competência e novo perfil do trabalhador moderno}

A ideia de qualificação sempre ocupou posição de destaque dentro dos estudos das diversas áreas do conhecimento, em especial da educação e da sociologia do trabalho, tendo se consolidado na França, após a Segunda Guerra Mundial, quando se estrutura o ensino profissional e organizam-se os saberes em torno dos diplomas (DUGUÈ apud COSTA, 2007). A qualificação estrutura, nesse momento, a ligação entre o saber fazer, o emprego e o salário, de forma que a relação de emprego deveria estar em consonância com as condições gerais estabelecidas.

Dois são os caminhos pelos quais a qualificação tem sido compreendida, um deles defendido por Georges Friedmann e o outro por Pierre Naville. Segundo Friedmann (1973), o artesanato deveria ser considerado a forma perfeita do trabalho qualificado. Dessa forma, sua degradação pela via da divisão do trabalho geraria os maiores problemas da sociedade e organização industrial. Para o autor, a qualificação ocorria pelo saber e pelo saber-fazer adquiridos tanto no trabalho (aprendizagem informal) quanto em sua aprendizagem sistemática (aprendizagem formal). Seria, portanto, construída a partir do posto de trabalho e encontrava-se no trabalhador.

Já para Naville (1956), a qualificação é o resultado de um processo de formação autônomo, ou seja, independente da formação no trabalho. Em seu entendimento, a qualificação dependeria do ambiente social do trabalhador, do estado das forças produtivas e das estruturas socioeconômicas nas quais os trabalhadores estivessem inseridos, tais como tempo de escolarização, salário, operações de classificação e hierarquia do trabalho. Acreditava, portanto, que a qualificação não é determinada pela tecnologia, mas construída socialmente, não sendo automaticamente especificada pelo conteúdo do trabalho.

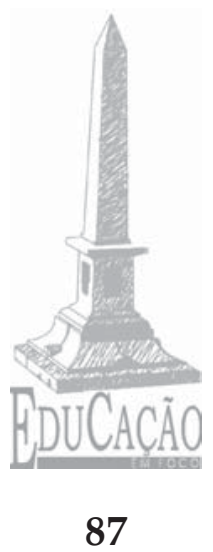


Complementarmente, Segnini (2001) entende que as habilidades, conhecimentos, visão de mundo etc. que o trabalhador adquire na sua relação com as instituições e com os outros homens só se transformam em valor de troca no momento em que o capital reconhece essas características como relevantes. Nesse sentido, "escolaridade e formação profissional são condições necessárias, mas insuficientes, para o desenvolvimento social" (SEGNINI, 2001, p. 21).

Assim, ante a nova disposição dos processos produtivos (utilização de células de produção, por exemplo, que rompe com o tradicional posto de trabalho) surge a necessidade de se forjar a multiqualificação ou a polivalência ${ }^{4}$ a partir dos processos de formação profissional. Rediscute-se, assim, a noção de qualificação e a utilização de um novo conceito, o de competência (CARRILO, 1994).

O conceito de competência, apesar de utilizado há mais tempo em outras áreas do conhecimento, surge nos estudos sobre o trabalho diante da ênfase dada à "polivalência". As novas capacidades necessárias ao trabalhador não estariam mais limitadas à informação técnica, mas também a habilidades cognitivas e características comportamentais e atitudinais como se vê em Tartuce:

[...] capacidades de abstração, de raciocínio, de domínio de símbolos e de linguagem matemática para a leitura de modelos e antecipações de problemas aleatórios e imprevistos; iniciativa, responsabilidade, compromisso, cooperação, interesse, criatividade, capacidade de decisão, para o trabalho em equipe, para a visualização das regras de organização, das relações de mercado etc. (TARTUCE, 2002, p. 135).

Já na visão de Hirata (1994), o conceito de competência, no que diz respeito a sua utilização nas discussões sobre trabalho, teve origem na retórica empresarial há 20 anos, na França, e foi retomado em seguida por economistas e sociólogos. Ele surgiu da necessi-

${ }^{4}$ Salerno (1994) faz a seguinte distinção entre trabalhador multifuncional e trabalhador multiqualificado: enquanto o primeiro se caracteriza por operar mais de uma máquina com características semelhantes - o que pouco lhe acrescenta em termos de desenvolvimento equalificação profissional-, o segundo desenvolve e incorpora diferentes habilidades e repertórios profissionais. 
dade de classificar e definir novos conhecimentos e habilidades criadas a partir das novas exigências de situações profissionais, tendo sido um conceito associado aos novos modelos de gestão.

Quanto ao Brasil, a noção de competência, apesar de já ser conhecida no âmbito das ciências humanas desde a década de 1970, é nos anos de 1990 que ela passa a ser incorporada nos discursos dos empresários e dos técnicos dos órgãos públicos que lidam com o trabalho. A competência surge como se fosse uma consequência natural do processo de transformação das formas de organização do trabalho.

Usado de forma genérica, o termo competência tem sido utilizado cotidianamente na educação e no trabalho como se possuísse uma conotação universal. Para os empresários, há uma disposição a entender a competência como "estoque de conhecimentos/habilidades", mas principalmente como capacidade de iniciativa e preparação para atuar em situações adversas ou previsíveis (LEITE, 1994).

Ao comparar a visão tecnicista de qualificação amplamente aceita pela visão taylorista/fordista do processo de organização do trabalho com o modelo da competência desenvolvido a partir do toyotismo, nota-se que as duas vertentes entendem a qualificação proveniente de um modelo de organização capitalista do trabalho. Podem-se distinguir as duas visões, no entanto, a partir de seus aspectos qualitativos: a primeira é a qualificação mais restrita, limitada do ponto de vista técnico-científico e a segunda, em patamares mais abrangentes, levando em conta fatores mais subjetivos e psicossociais.

Surge, então, a busca das organizações por uma educação continuada e/ou aprendizagem contínua. A organização exercita a sua capacidade em responder ao seu ambiente interno (objetivos, metas, resultados) e ao mercado (estratégia). Tais organizações, as que abraçam esses ideais, podem ser entendidas como Organizações de Aprendizagem. Segundo Senge:

nas organizações que aprendem, as pessoas expandem continuamente sua capacidade de criar resultados que elas realmente desejam, onde maneiras novas e expansivas de pensar são encorajadas, onde a aspiração

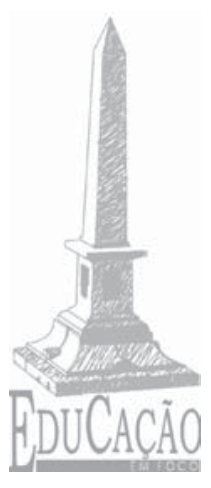

89 
coletiva é livre, e onde as pessoas estão constantemente aprendendo a aprender coletivamente (SENGE, 2000, p. 40).

No mesmo sentido intrínseco, nomeia Zarifian (2001) as "organizações qualificantes". Nelas a aprendizagem e a aquisição de experiências na interação com eventos, problemas encontrados e solução dos mesmos podem levar o indivíduo a um respeitável desenvolvimento pessoal, permitindo que pessoas com pouco tempo na empresa adquiram rapidamente uma grande experiência.

Porém, não se aprende apenas através de estímulos externos coordenados. Os indivíduos estão em permanente estado de aprendizagem, quer estejam sós ou em sociedade. A reflexão sobre a realidade perceptível, de forma intencional ou não, tem como propósito ancestral desenvolver nossa relação com o meio ambiente, tendo em vista a nossa sobrevivência. A mente humana encontrase sempre em atividade, não importa se nos entendemos acordados ou não. Durante o sono, organizamos as informações adquiridas durante o dia para uso posterior (NEVES, 2007). Segundo a autora, apesar de estar conscientemente recuperando informações adquiridas para atender suas demandas na sociedade, o indivíduo não se dá conta do potencial presente nessa gestão cognitiva e no controle que pode exercer sobre seus processos mentais. Quando se dá conta desse potencial, não apenas refletindo como realizar as tarefas do cotidiano, mas também como adquirir novas informações, aí sim, ele alcança a capacidade de "aprender a aprender". Esse processo foi discutido pela primeira vez por Flavell (1979), que o denominou metacognição.

\section{Resultados obtidos}

\subsection{Aprendizagem formal}

Desde cedo, o trabalho está presente na vida dos entrevistados, exercendo um importante papel em suas práticas sociais e, às vezes, 90 influenciando os relacionamentos familiares. Nesse quadro, a esco- 
la formal está cada vez mais presente, apesar das necessidades de sobrevivência que forçaram vários deles a uma entrada prematura no mercado de trabalho. Tal aspecto contribuiu para que a escolarização desse grupo, em alguns casos, não tenha se dado de forma adequada. Vários dos entrevistados não terminaram seus estudos do ensino fundamental ou médio. Com a maior parte deles, houve interrupção dos estudos antes ou durante o ensino médio.

Para muitos, a entrada na empresa significou atingir um perfil estável de renda, o que os estimulou a formarem famílias. Poucos são os empregados da empresa que não se casaram.

Com a mudança das condições socioeconômicas dos entrevistados, a perda do papel privilegiado do trabalho na socialização de seus filhos, a escola passa a ser vista como meio de ascensão social, como fonte da possibilidade de uma vida melhor por preparar para uma profissão mais valorizada socialmente. Percebe-se um pouco disso na fala do mais jovem dos entrevistados, com 23 anos, quando diz que gostaria de terminar os estudos com um curso de engenharia e trabalhar no setor de projetos.

Ao serem perguntados sobre sua formação, os entrevistados deixaram claro que ligam a ideia de educação e emprego diretamente. Exemplos práticos disso puderam ser vistos na organização a partir dos vários casos de trabalhadores que, mesmo depois de anos sem estudar, trabalhando em setores de tarefas altamente prescritivas, reiniciaram seus estudos, formaram-se e quando do surgimento de vagas, foram aproveitados em outros setores da empresa. Tal situação aconteceu, sobretudo, com trabalhadores do laboratório, todos vindos do setor de montagem (por exemplo, o entrevistado 11). Alguns inclusive foram promovidos além, para setores considerados mais exigentes em experiência como o de suporte técnico (entrevistado 09).

Em entrevista, a gerente de recursos humanos afirmou que estimula ao estudo todos os que mostram algum interesse (confirmado em depoimento de outros empregados), inclusive liberand o o trabalhador que faz curso de engenharia ou técnico em eletrônica de

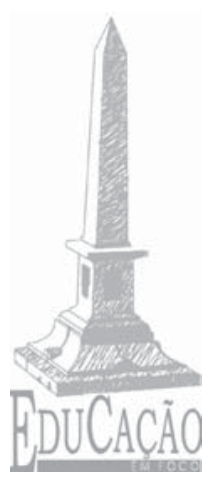

91 
horas de seu trabalho diário para fazer estágio técnico na própria empresa. No entanto, a gerente diz se preocupar, pois não é possível promover todos ao cargo de técnico de eletrônica.

O fenômeno pode ser facilmente explicado em Bourdieu. Para ele, apesar de a família ser o local do início da socialização do indivíduo, a escola é um lócus privilegiado para formação do habitus, pois pode contribuir, e infelizmente muitas vezes o faz, para reprodução da estrutura de relações de classe, assumindo a função social de legitimar e conservar privilégios e vantagens sociais das classes dominantes, ou seja, o mesmo papel da Igreja na Idade Média. Outra possibilidade não menos perversa é a de instrumentar ideologicamente as práticas sociais, contribuindo para a disseminação do ideário de determinada classe e desenvolvendo seguidores, seja ela uma classe dominante ou não.

No entanto, a escola hoje é vista por muitos como uma instituição aparentemente neutra, científica e perfeitamente aceitável dentro de um sistema democrático. Àqueles que a ela têm acesso, ela proporciona a posse de títulos escolares que cada vez mais são associados a uma posição diferenciada no espaço social. Segue a fala do entrevistado 11 .

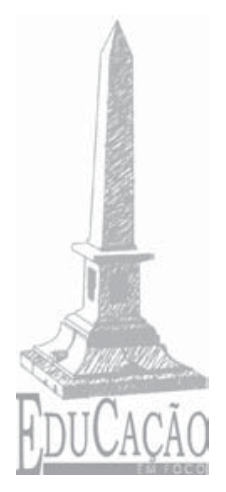

92

Meus pais são do interior, viemos para cá em 1996, não tinha segundo grau e continuei estudando. Entrei no setor de transformadores (por três anos) e fui para o setor de bobinas onde fiquei por nove anos. Na verdade eu sempre quis ter um pouco mais de condições nas coisas. Eu estudei um pouco para melhorar, e fiz o curso técnico também para subir, ter uma oportunidade na empresa. Em momento algum eu fiquei parado, às vezes eu fiquei parado por condições. Por exemplo, antes de vir para cá eu não tinha condições de estudar, a cidade mais próxima era a 12 quilômetros, aí ajudava meu pai na roça. Quando cheguei, eu fiz o segundo grau, o curso técnico, pedi uma oportunidade e me deram. Não tive dificuldade em mudar 
de setor. Tudo que precisei aqui, nunca tive dificuldade.

Esse depoimento mostra que o trabalho está presente na vida desse entrevistado desde quando ele era criança e tem grande importância na formação das práticas sociais dos indivíduos. Isso não significa que a escola não tenha um papel, mas que ela ocupa um caráter secundário ante a necessidade da sobrevivência. Isso acaba gerando problemas para a conclusão dos ciclos escolares. Mas mesmo na zona rural, como é o caso do entrevistado 11, há a ideia de que criança deve ir para a escola. O que gera estranhamento é que ante a colocação da escola formal em segundo plano por tanto tempo (em relação a história de vida do entrevistado 11), houve a formação de uma disposição tão forte que o levou a querer estudar, mostrando estar presente no referencial simbólico do entrevistado. Uma explicação para isso poderia ser a influência da cultura organizacional de uma empresa onde os processos de qualificação internos são muito frequentes, pelo menos em alguns setores como o laboratório.

Notou-se, a partir das entrevistas e interações com os trabalhadores durante o período de observação, que para os entrevistados nascidos ou criados no meio urbano, o abandono da escola, quando ocorre, acontece durante o ensino médio. A escolarização até o ensino fundamental ocorre sem interrupção. No entanto, em alguns casos, ocorre depois do previsto. A escola, como se viu na citação do entrevistado 11, passa a ser vista como meio de ascensão social, como possibilidade de atingir uma vida melhor, o que foi buscado pelo entrevistado. Nem sempre esse processo tem sucesso por diversos motivos (não é possível promover a todos sempre, por exemplo). Dessa forma, aparece também na fala dos entrevistados a relativização dessa possibilidade, expressão do habitus de classe, imposto pela realidade objetiva, criando disposições e predisposições que levam à resignação frente ao possível fracasso da empreitada. Essa interpretação é confirmada na entrevista com a gerente de recursos humanos, que tem como responsabilidade o

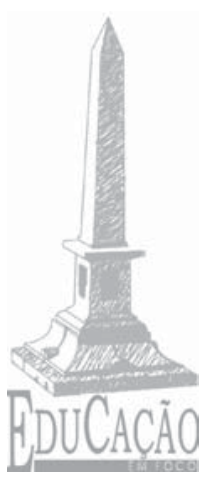

93 
acompanhamento dos trabalhadores em seu processo de crescimento na empresa.

O trabalhador da produção da empresa estudada vê seus diretores e grupo de empregados do projeto como alguém para quem o processo funcionou: doutores, mestres, engenheiros, pessoas que vieram do ambiente acadêmico e que por isso, ocupam posições de destaque na empresa. Afinal, os melhores cargos nas empresas e as melhores posições sociais são ocupados por pessoas que passaram por universidades renomadas, tiveram uma longa escolaridade e investiram na sua qualificação/competências. E na medida em que a empresa busca apoiar esse comportamento, reforça no campo social o habitus criado na escola.

Quando se trata da recuperação da sua própria escolaridade atrasada, todos os entrevistados deixam claro o quanto julgam a educação importante, especialmente a educação formal. Isso se observa principalmente naqueles que superaram dificuldades para retomar os estudos (caso, por exemplo, do Entrevistado 9, que ficou oito anos sem estudar, conseguiu romper com o imobilismo e se formou técnico), como a disposição de enfrentar a carga representada pela jornada de trabalho aliada a mais um período de estudo. Essa importância foi observada tanto nos trabalhadores com escolaridade mais baixa quanto nos possuidores de curso superior, inclusive mestres que se sentem compelidos a desenvolver sua pesquisa na empresa, uma prática comum. Vários motivos levaram aqueles que não obtiveram ainda o ensino médio ou técnico a voltar à escola: como melhoria de perspectivas profissionais e chances perdidas ou por ser uma ferramenta para melhoria de vida. O conhecimento é visto como um capital individual do qual a pessoa se apropria e dispõe como bem entender, elemento de individuação e distinção numa busca solitária pela melhoria da qualificação.

Já os possuidores de curso superior ou mestres acreditam que o estudo não gerará mudanças imediatas em sua vida, mas que pode mantê-los na posição que têm atualmente.

A empresa promove também treinamentos formais, ainda que 
poucos, quando do lançamento de novos produtos e principalmente os ligados à Comissão Interna de Prevenção de Acidentes (Cipa).

Talvez seja na área de segurança do trabalho que se faz mais evidente como as práticas sociais do trabalhador podem ser modificadas. Apesar de valorizadas, as atividades promovidas pelo setor de segurança do trabalho não são entendidas pelos trabalhadores como formação, mas como de caráter técnico. Tais treinamentos, no entanto, promovem algumas mudanças entre os trabalhadores como, por exemplo, na necessidade de construírem redes de proteção mútua para prevenir acidentes (todos orientando a todos quando se vê uma situação insegura). Alguns sentem que mudaram seu modo de ser. Evidentemente, essa modificação em relação à segurança vai ao encontro de problemas desde sempre vivenciados pelos trabalhadores, pois são eles que sofrem diretamente as consequências das condições de trabalho inseguras.

\subsection{Aprendizagem informal}

Todos os entrevistados mencionaram ter recebido algum tipo de instrução em maior ou menor quantidade em serviço. O tempo de instrução para qualificarem-se minimamente para suas funções variou de seis meses a um ano. Na opinião de todos, esse período se deveu ao grande número de produtos do portfólio da empresa.

A cultura de treinamento em serviço permeia todos os setores da empresa. Os trabalhadores têm consciência disso, sendo assim, relacionar-se bem com os colegas é fator fundamental para manutenção de seu emprego.

Essa forma de aprendizagem, prática e calcada em relações pessoais, atualiza na empresa práticas sociais desenvolvidas a partir daquelas já vividas em relações familiares anteriores. Ocorre também na empresa casos como o do entrevistado 7, que trabalha no mesmo setor que seu pai. A qualificação vai se forjando no tempo devido ao desejo de progressão funcional e de outros fatores como habilidade em se relacionar, capacidade de observação, curiosida-

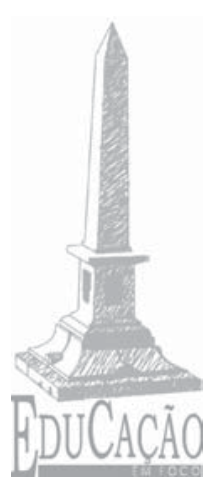

95 
de e interesse em aprender. Vale ler a opinião do entrevistado 7.

Uma palavra que caracteriza bem minha relação com meus colegas de empresa é a amizade, outra a união do grupo para trabalhar. Acho muito difícil, pode até existir, mas nunca vi ninguém tentando passar o outro para trás, por exemplo, não vou ensinar isso para essa pessoa porque senão ela pode tomar minha vaga aqui. Tudo que peço para me ensinar a pessoa pega e me ensina, senta comigo e diz é assim, assim, assim. Não pode fazer isso, por isso, e isso, e isso.

Segundo a gerente de recursos humanos, participar e mostrar assimilação de conhecimentos na aprendizagem informal direta disponibilizada é fator importante, mas não é suficiente para que se desenvolva uma qualificação que permita ascender dentro da empresa. Todos são acompanhados e avaliados constantemente também a partir de aspectos subjetivos por ela, pelo supervisor e pelo coordenador de produção.

\subsection{Das práticas sociais de interação e setoriais na empresa}

A empresa é muito querida pelos trabalhadores que se sentem amparados e seguros, apesar de recentemente ter acontecido um processo de demissões que afetou cerca de $25 \%$ do efetivo. Entendem a crise atual como "culpada", da mesma forma que viveram crises anteriores e foram recontratadas as pessoas demitidas.

Nas visitas ocorridas durante esses dois anos em que foi desenvolvida a pesquisa, um dos fatos passíveis de observação foi o relacionamento amistoso entre as pessoas. O pesquisador sempre foi muito bem recebido. No momento em que começou a frequentar a empresa com mais assiduidade, não só foi reconhecido e apoiado em suas necessidades de pesquisa como os trabalhadores mostraram um interesse legítimo na atividade, perguntando sobre seu andamento e se poderiam fornecer mais alguma informação.

Todos os trabalhadores têm acesso aos proprietários da empre- 
sa, que ocasionalmente circulam pelos galpões da produção e implantaram uma cultura interna de aproximação entre as pessoas. Por exemplo, todos fazem as refeições no mesmo lugar e se alimentam da mesma comida, desde os diretores e administrativo até o membro mais humilde do setor de transformadores. Essa política também permeia as regras de convivência. Uma regra aplicada vale para toda a empresa como um todo, não existindo exceções.

Os engenheiros do setor de projeto que frequentam a produção mantêm uma relação especial com alguns interlocutores privilegiados (um deles supervisor, o restante profissionais outros), pessoas que interagem com os mesmos na busca de soluções para problemas de desenvolvimento físico do projeto. Formalmente seu contato deveria ser com o coordenador de produção, mas parecem se valer melhor de uma boa conversa com algumas pessoas na produção. Uma dessas pessoas foi o entrevistado 11:

Quando trabalhava na bobinadeira não fazia apenas bobinas, criava ferramentas para projetos novos e ajudava a desenvolver protótipos de novas bobinas. [...] Às vezes deixávamos uma atividade da produção para atender ao pessoal do projeto.

Em verdade, durante todo o processo de pesquisa, a impressão que se tem é de que toda a empresa gira em torno do setor de projetos.

A figura dos engenheiros do projeto perpassa o simbólico dos membros do setor de transformadores e bobinas como pessoas admiráveis e que "sabem tudo". No laboratório, o setor é visto como um lugar onde as coisas "acontecem" e "onde eu gostaria de trabalhar".

Apesar de, em princípio, as atividades do laboratório estarem alinhadas à produção, seus membros se sentem mais próximos dos engenheiros de projeto. Todas as placas-protótipo são feitas no laboratório e a relação entre os setores é intensa e profícua. Os membros do laboratório também têm acesso ao pessoal do projeto através de computadores (um em cada bancada), assim como a todos os diagramas das placas e equipamentos para reparar os

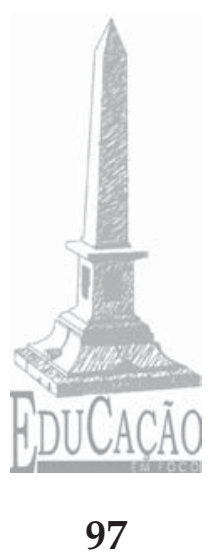


defeitos quando surgem. Estabeleceu-se, assim, um canal privilegiado de troca e interação que não existe na produção.

\subsection{Dos processos interativos de alta complexidade}

A organização estudada constituiu-se em um interessante caso de estudo, uma empresa de alta tecnologia que ainda usa na fabricação de seus aparelhos paus e pedras, ou melhor, apenas paus (o núcleo das bobinadeiras é de madeira assim como o martelo). Causa espécie na organização estudada, algumas situações ali encontradas se remetem a paradoxos. Um exemplo, ser uma organização que manufatura um produto tecnologicamente avançado com técnicas de gestão que remetem ao século passado e a necessidade, hoje, de lutar para sobreviver no mercado como uma empresa de capital nacional e sem exportar, mantendo altos índices de participação nesse mesmo mercado (sob pena de deixar de existir) e concorrendo com empresas de maior porte e tecnologia similar. Se o seu exterior parece remeter a paradoxos, já foram encontrados alguns elementos conhecidos em seu interior.

Da observação feita e dos depoimentos colhidos em diversos momentos, trabalhadores admitem acumular informações e nem sempre trabalhá-las em processos de assimilação formal. Os repetidos treinamentos a que são submetidos ocasionalmente parecem confirmar isso. Chamaram a atenção em especial a atitude e respostas do entrevistado 6. De um pensamento bastante rígido em suas convicções, em várias de suas falas, citou frases que caracterizam muito bem seu setor de trabalho:

[...] Eu modifico a forma de executar o trabalho, conforme a forma que for definido, independente do que acho.[...] tem um documento e a gente segue a norma do documento, aí a gente tá sempre atualizando em cima do documento.[...] Eu recebo e executo.[...] É importante quanto mais a gente receber informação é melhor, a gente pode abranjar mais é bom. 
Essas falas são também em parte reproduzidas por outros entrevistados como, por exemplo, os entrevistados 4 e 5 . Isso mostra que o aprendizado não necessariamente significa mudança, hipótese válida independentemente de setores ou mesmo de escolaridade. $\mathrm{Na}$ verdade, aparece aqui um processo que extrapola a vontade do sujeito, uma disposição prática. Os atores parecem reagir à sua própria situação funcional. Identificam-se com o papel de fazedores e se mostram dóceis com ele. Não significa que estão efetivamente satisfeitos com isso, não há como afirmá-lo ou não sem um estudo que demandaria técnicas especiais de análise de comportamento.

Não pense que o pesquisador se furta a considerar as ordens da estrutura, que pela mão de um setor, o de projetos, estabelece os parâmetros das mudanças.

Mas é tão simples mudar, inovar, melhorar? Isso não parece ter uma resposta fácil. Situações que geram essas circunstâncias se constituem comumente em problemas de características e complexidade diversas que se manifestam. E essa pesquisa mostrou alguns exemplos, de forma inversamente proporcional à interação entre os sujeitos do processo. Não que a simples presença humana por si só iniba as dificuldades encontradas nas situações de trabalho, mas sim quando esses sujeitos interagem a partir de parcerias sinérgicas. Ou seja, quando esses sujeitos se dispõem a expor, confrontar e aproximar as informações de que dispõem na busca da formação de práticas de transformação e mudança.

O discurso da mudança, da inovação e da melhoria contínua induz o pesquisador à reflexão de que esse discurso não se constitui, nessa empresa, somente em oportunidades de participação do trabalhador em processos de trabalho não estandardizados (fabricação de protótipos, por exemplo). As "sugestões", do ponto de vista dos trabalhadores, seriam manifestações inconscientes do sujeito que quer dizer "eu penso", , eu também entendo disso", , eu posso contribuir nesse grupo" e que, quando conseguem efetividade na proposta, essa pode se materializar no campo em uma nova prática que deverá ser documentada e reproduzida por

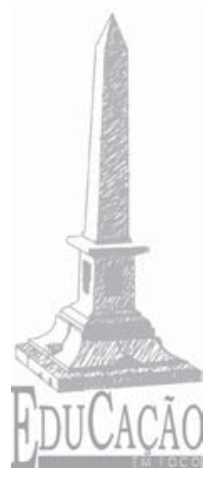

99 
todos (MOREIRA, 2009; 2006).

A necessidade da produção flexível profissional exige novo perfil, mas ainda se convive com setores de fundo taylorista como a bobinagem. A válvula de escape social para alguns é sua participação através de sugestões ou, para alguns interlocutores privilegiados da equipe de projetos, o trabalho conjunto em protótipos de novos produtos. Durante a pesquisa, foram contatadas pelo menos três dessas pessoas (entrevistados 2, 9 e 11) que acabaram sendo promovidos ou saindo de seus setores de origem para outros setores onde deveriam solucionar problemas de alta complexidade. Propor algo para uma equipe de projeto (de conhecimentos incontestáveis) significa muito para o trabalhador que ao mesmo tempo auto afirma-se como pensador.

\section{Considerações finais}

Ao pesquisar se as estratégias de aprendizagem nas organizações, expressas nos programas de qualificação para o trabalho, podem ser geradoras de mudanças nas práticas sociais dos trabalhadores no ambiente profissional, os pesquisadores preocuparam-se, sobretudo, em que bases esse estudo se construiria. Pierre Bourdieu, Anthony Giddens e Phillip Zarifian foram escolhidos dentre muitas outras possibilidades por centrarem seus estudos em dois aspectos que desde sempre interessaram: o subjetivo na ação das pessoas, contemplado de maneira clara no trabalho dos dois primeiros autores, e o trabalho, ênfase dos escritos do terceiro. Cabe aqui tratar de apresentar considerações finais a partir do que se considera já ter sido prenunciado nas diversas observações feitas durante o processo de análise deste texto.

Como se viu, o trabalhador quer produzir melhoria nos produtos para alterar a maneira como faz as coisas (quer romper com suas práticas, mudar). Ao mesmo tempo, a empresa quer melhorias porque geram aprimoramentos dos projetos (resultados de processos de aprendizagem na organização). Melhoria de projetos e pro- 
cesso podem gerar assim interações no campo (na medida em que buscam, por exemplo, a reorganização do trabalho) ou gerar modificações na estrutura em um processo reflexivo.

Ao agente (que não é consciente disso) é "permitido participar", agir (não que precise dessa permissão, mas se alivia ao recebêla sem lutar). E dessa ação pode advir a mudança. Mas o apelo à participação (ainda que consentida) não pode ou deve ser aceito por todos em essência. A qualificação o viabiliza e seu preço é a assimilação pelo capital do implícito ou imaterial, a doação de cópias e fragmentos de si.

Os trabalhadores, nessa linha de pensamento, mostram-se como atores reflexivos. Buscam conscientemente a melhoria contínua que viabiliza seu emprego, mas desejam (inconscientemente) a possibilidade de furtar-se das práticas de trabalho estabelecidas pela estrutura, ainda que no fragmento de uma sugestão. Assim, contribuem para uma lenta e sutil recriação do campo, a empresa.

Pode o trabalhador furtar-se a fazê-lo? Em princípio sim, mas contrariaria as disposições do campo, o que significa dizer: romper com a cultura da empresa e assumir consequências disso. Mantém-se, assim, a capacidade de ação pela prerrogativa, mas o campo impõe a consequência. A abstração aqui tratada tanto atende a visão de Giddens, no que se consubstancia do processo de agência pertencer ao domínio subjetivo interior do homem, quanto ao reconhecimento das externalidades ao sujeito inscritas no campo.

Assim, os processos de resignificação simbólicos na empresa pela geração de novos saberes seriam consequentemente desdobramentos de tentativas e de sucessos na criação de pequenas rupturas com as práticas sociais no trabalho a partir da interação dos indivíduos e da necessidade de inovação imposta pelo mercado.

Dessa forma, pode-se inferir o que foi evidenciado neste trabalho: tanto a construção da identidade do trabalhador moderno enquanto assalariado a partir da construção social do conhecimento no trabalhar, como a construção de novos saberes que se consubstancia em novas práticas profissionais.

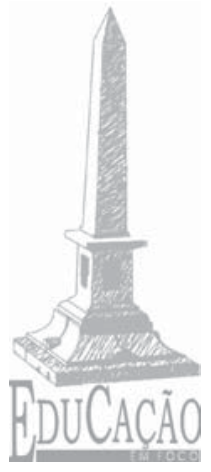

101 


\section{Referências}

BOURDIEU, P. Campo do poder, campo intelectual e habitus de

classe. In: . Economia das trocas simbólicas. 3. ed. São Paulo: Perspectiva, 1992.

FLAVELL, J. H. Metacognition and cognitive monitoring: a new area of cognitive-developmental inquiry. American Psychologist, Washington, v. 34, p. 906-911, 1979.

FRIEDMANNN, G.; NAVILLE, P. Tratado de sociologia do trabalho. São Paulo: Cultrix, 1973. v. 1.

GIDDENS, A. A constituição da sociedade. São Paulo: Martins Fontes, 1990.

HIRATA, H. Da polarização das qualificações ao modelo de competência. In: FERRETTI, C. J. et al. Novas tecnologias, trabalho e educação: um debate multidisciplinar. Petrópolis: Vozes, 1994.

LEITE, M. de P. O futuro do trabalho: novas tecnologias e subjetividade operárias. São Paulo: Scritta, 1994.

MOREIRA, A. Aprender e trabalhar: paradoxos e novos significados. Revista CEREC Facesm, Itajubá, v. 8, n. 8, p. 13-22, 2006.

Qualificação e práticas sociais no trabalho assalariado: o aprender em uma indústria no século XXI. Tese (Doutorado em Ciências Sociais: Sociologia) - Programa de Doutorado em Ciências Sociais, Pontifícia Universidade Católica de São Paulo, 2009.

NAVILLE, P. Essai sur la qualification du travail. Paris: Librairie Riviere, 1956. 
NEVES, D. A. de B. Meta-aprendizagem e ciência da informação: uma reflexão sobre o ato de aprender a aprender. Perspectivas das Ciências da Informação, Belo Horizonte, v. 12, n. 3, set./ dez. 2007.

SEGNINI, L. Constantes recomeços: desemprego no setor bancário. In: BRUSCHINI, C; PINTO, C. R. (Orgs.). Tempose lugares de gênero. São Paulo: Fundação Carlos Chagas, 2001.

SENGE, P. M. A quinta disciplina - caderno de campo: estratégias e ferramentas para construir uma organização que aprende. Rio de Janeiro: Qualitymark, 2000.

TARTUCE, G. L. B. P. O que há de novo no debate da qualificação do trabalho?: reflexões sobre o conceito com base nas obras de Georges Friedmann e Pierre Naville. Dissertação (Mestrado em Educação) - Faculdade de Filosofia, Letras e Ciências Humanas, Universidade de São Paulo,São Paulo, 2002.

ZARIFIAN, P. Objetivo competência: por uma nova lógica. São Paulo: Atlas, 2001.

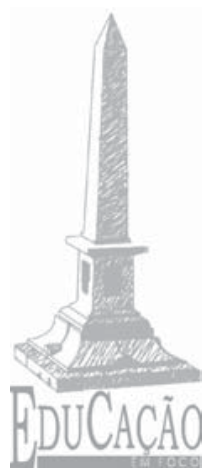




\title{
The learning as a factor of change in organizations
}

\begin{abstract}
The study presented here is part of a new perspective. Search will show a bit of subjectivity in human relations at work, more precisely how the learning can produce changes in social practices at work. The theoretical link was forged from concepts established in Phillipe Zarifian, Pierre Bourdieu and Anthony Giddens. The field reserch had place at an industrial organization, leadership on eletronics goods, located at Contagem / MG. The informations were obtained from interviews with employees on charge of many functions and sectors on the organization as well as thorough immersion in the industry daily skills. Its use in the analysis that allowed us to construct theoretical and actual articulation of the authors, making it possible to conclude that learning may be an important catalytic element of processes of reflexibility in organizations, as a result of itself changes.
\end{abstract}

Keywords: Learning; qualification; habitus; reflexibility. 